\title{
Inequities in access to health care in different health systems: a study in municipalities of central Colombia and north-eastern Brazil
}

Irene Garcia-Subirats ${ }^{1,2^{*}}$, Ingrid Vargas ${ }^{1}$, Amparo Susana Mogollón-Pérez ${ }^{3}$, Pierre De Paepe ${ }^{4}$, Maria Rejane Ferreira da Silva ${ }^{5}$, Jean Pierre Unger ${ }^{4}$, Carme Borrell $^{6,7,8}$ and Maria Luisa Vázquez ${ }^{1}$

\begin{abstract}
Introduction: Health system reforms are undertaken with the aim of improving equity of access to health care. Their impact is generally analyzed based on health care utilization, without distinguishing between levels of care. This study aims to analyze inequities in access to the continuum of care in municipalities of Brazil and Colombia.

Methods: A cross-sectional study was conducted based on a survey of a multistage probability sample of people who had had at least one health problem in the prior three months (2,163 in Colombia and 2,167 in Brazil). The outcome variables were dichotomous variables on the utilization of curative and preventive services. The main independent variables were income, being the holder of a private health plan and, in Colombia, type of insurance scheme of the General System of Social Security in Health (SGSSS). For each country, the prevalence of the outcome variables was calculated overall and stratified by levels of per capita income, SGSSS insurance schemes and private health plan. Prevalence ratios were computed by means of Poisson regression models with robust variance, controlling for health care need.

Results: There are inequities in favor of individuals of a higher socioeconomic status: in Colombia, in the three different care levels (primary, outpatient secondary and emergency care) and preventive activities; and in Brazil, in the use of outpatient secondary care services and preventive activities, whilst lower-income individuals make greater use of the primary care services. In both countries, inequity in the use of outpatient secondary care is more pronounced than in the other care levels. Income in both countries, insurance scheme enrollment in Colombia and holding a private health plan in Brazil all contribute to the presence of inequities in utilization.

Conclusions: Twenty years after the introduction of reforms implemented to improve equity in access to health care, inequities, defined in terms of unequal use for equal need, are still present in both countries. The design of the health systems appears to determine access to the health services: two insurance schemes in Colombia with different benefits packages and a segmented system in Brazil, with a significant private component.
\end{abstract}

Keywords: Access to health care, Inequities, Primary health care, Secondary care, Emergency care, Preventive health services, Colombia, Brazil

\footnotetext{
* Correspondence: igarcia@consorci.org

'Health Policy and Health Services Research Group, Health Policy Research Unit, Consortium for Health Care and Social Services of Catalonia, Avenida Tibidabo, 21, Barcelona 08022, Spain

${ }^{2} \mathrm{Ph}$. D. Programme in Biomedicine, Department of Experimental and Health

Sciences, Universitat Pompeu Fabra, Barcelona, Spain

Full list of author information is available at the end of the article
} 


\section{Introduction}

In an egalitarian approach, based on the notion of social justice, equity is defined either as equal treatment for equal need (horizontal equity) or as different treatment for different needs (vertical equity) [1]. In health services research [2-7] access is usually analyzed based on the notion of horizontal equity, which would be considered to exist when access is dependent on need and not on other socioeconomic or demographic factors [8].

Colombia and Brazil are the most populous countries of Latin America. With a Gross Domestic Product (GDP) per capita of $\$ 7,752$ and $\$ 11,340$ (US dollars) respectively in $2012[9,10]$, they are both classified as middle income countries [11]. Despite the gains in recent years in terms of poverty reduction and improvements in the Gini index [12], they still have the highest Gini coefficients in Latin America: in 2009, 0.57 [9] and 0.55 respectively [10], indicating considerable inequalities in income distribution. The illiteracy rate in Colombia (6.4\%) is lower than the Latin American average (7.8\%) and that of Brazil (9.6\%) [13]. Public health expenditure as a percentage of the GDP was 4.6\% in Colombia and 4.1\% [9] in Brazil in 2011 [10]. They have similar life expectancy at birth (74.0 in Colombia and 73.9 in Brazil) which is close to the Latin American average [13], while the infant mortality rate is slightly higher in Colombia (18.4 per 1000 live births) than in Brazil (15.3 per 1000 live births) or Latin America in general (16.3 per 1000 live births) [13].

Both countries reformed their health systems more than two decades ago with the common objective (among others) of improving equity of access, but they opted for different models. Colombia introduced the General System of Social Security in Health (Sistema General de Seguridad Social en Salud or SGSSS in Spanish), based on managed competition and made up of two insurance schemes: the contributory scheme, for formal sector employees and those able to pay, and the subsidized scheme for the low income population. Those that do not manage to enroll in either of the two schemes remain uninsured. Health insurance is managed by healthcare insurers (Empresas Promotoras de Salud or EPS in Spanish) for both the contributory scheme (EPS-C) and the subsidized scheme (EPS-S). Competition was introduced between insurers for the enrollment of the population and they receive a capitation payment to cover different benefits packages in each scheme: the Obligatory Health Plan (Plan Obligatorio de Salud or POS in Spanish) for the contributory scheme and the Obligatory Health Plan - Subsidized (POS-S) for the subsidized scheme [14], with fewer services than the POS. The insurers are responsible for organizing their own network of health providers for their enrollees. The providers are different for the two schemes.
Competition for contracts with the insurers was also introduced among public and private healthcare providers (Instituciones Prestadoras de Salud or IPS in Spanish). The uninsured population, 12.1\% [15], receives care in public healthcare service networks which are organized by regional and local health authorities [16].

In Brazil, the health sector is made up of two subsystems: on one side, the Unified Health System (Sistema Único de Saúde or SUS in Portuguese), conceived as a tax-funded national health system, decentralized according to the political structure of the country (federation, states and municipalities) and free at point of delivery [17], with care provided by public or contracted private providers; and on the other side, the private system (supplementary system), to which the population gains access via direct payment or private insurance schemes, which have their own network provider.

In both countries, care is organized by levels of complexity, with primary care as the entry point and care coordinator for the patient and the secondary level in a supporting role $[16,18]$. In the private healthcare subsystem, outpatient secondary care services can be accessed directly (via a private health plan or out-ofpocket payment).

The effects of these reforms on access in Brazil and Colombia have been analyzed indirectly through studying the design of the health system $[19,20]$, changes in coverage in the family health program in Brazil [21], or enrollment with an insurer in Colombia [22], and in a more direct way through looking at changes in utilization and equity in utilization before and after the reforms [23,24]. There are also studies available for both countries analyzing equity in the utilization of the health services, mostly based on national surveys of the general population: the Quality of Life Survey (Encuesta de Calidad de Vida, ECV) and the Demography and Health Survey (Encuesta de Demografia y Salud, EDS) in Colombia, and the National Household Sample Survey (Pesquisa Nacional de Amostra por Domicilios, PNAD) in Brazil. These studies indicate that, irrespective of need, individuals of a higher socioeconomic status - higher income [5,7,24-27], higher level of education $[23,25,28,29]$ or more favorable working conditions (stable employment) [30] - make greater use of the health services. In Brazil, people who have private medical insurance are shown to be more likely to use the health services [31]. These analyses, however, have certain limitations. In both countries, the analysis of equity in access focuses on the utilization of services in general $[5,6,26,27]$, without distinguishing between care levels, despite the international evidence showing that inequities vary between primary and secondary care [32-34], with the inequities being more pronounced in the latter. Only one study has been found for Colombia which 
differentiates utilization according to care levels [7] and there are none for Brazil. Likewise, equity in access to preventive services $[28,35,36]$ is a little explored subject matter. In Colombia, analyses also tend to focus on the differences between those covered by the SGSSS -either in general [24] or in the subsidized scheme [37,38]- and the uninsured, whilst studies comparing the use of services in the different insurance schemes are rare and give conflicting results $[27,28,39]$.

In both countries the studies tend to analyze inequities between large geographical regions (Departments or States) $[40,41]$, but not between smaller areas within these, although there are signs of inequities in access within regions, for example between the different localities in the city of Bogotá [42], a region with one of the highest percentages of health services utilization in Colombia [15]. In Brazil, the studies which analyze smaller areas mainly focus on the south of the country [43-46], and there are practically none for the northeast, despite this region having lower utilization rates than the national average and greater inequity in the use of the health services [40].

Lastly, equity of access in the health systems of Colombia and Brazil has been analyzed in the context of Latin American-wide studies which compare either the design of different health systems [1,47-49] or equity in utilization $[4,41,50]$. These are generally based on national surveys which were not designed for this purpose, so differences in the questions asked make them difficult to compare $[4,41]$. The only comparative study between the two countries analyzes inequities in health [51], but not in access to services.

Identifying the care levels in which there is inequity in utilization (and to what degree) in different health systems may contribute to the design of policies aimed at reducing this problem. The purpose of this study is to conduct a comparative analysis of equity in access to the health services distinguishing between different care levels (primary, outpatient secondary, emergency and preventive care) in two areas of Colombia and Brazil, focusing particularly on the role of insurance scheme enrollment in Colombia and the possession of a private health plan in Brazil.

\section{Methods}

\section{Design and study area}

A cross-sectional study was conducted by means of a population survey in central Colombia and the northeast of Brazil. The study areas were two municipalities in each country: in Colombia, Kennedy (a district of Bogotá) and Soacha; and in Brazil, two micro-regions (3.2 and 3.3) of District 3 in Recife, Pernambuco's capital, and Caruaru, in the interior of Pernambuco state. These four areas are the areas of the Equity-LA project (http://www2.equity-la.eu/), the broader Project in which this study is framed [52]. The areas were selected for being densely populated urban spaces with a high proportion of the population belonging to the low or mediumlow socioeconomic strata and with varying geographical access to specialist care. Kennedy has approximately $1,000,000$ residents and the other three study areas have about 300,000 residents. Kennedy and the two microregions of District 3 in Recife share the characteristic of being some of the more deprived areas in their respective cities.

\section{Study population and sample}

The study population was made up of residents in the study areas who had had at least one health problem or had used to the health services in the three months prior to the survey.

The sample size was calculated for each study area based on the population size and an estimated proportion of $50 \%$ (maximum uncertainty principle); degree of confidence: $90 \%$ (alpha error of 0.1 ); precision: 2.5 . The sample size was 2,163 in Colombia (1,083 in Kennedy, 1,080 in Soacha) and 2,155 in Brazil (1,076 in district 3 of Recife, 1,079 in Caruaru).

In both countries, multistage probability sampling was conducted. In the first stage, census tracts were randomly selected (in Soacha, from all six comunas - i.e. districts) with replacement. In the second stage, households were systematically selected. The sample range was calculated according to sample size and number of households in each neighborhood; the initial home was randomly selected. The household was considered the primary sampling unit to avoid the effect of associated samples in individuals belonging to a family.

\section{Questionnaire}

A questionnaire was designed to analyze access to health care. Based on the Behavioral Model of Health Services Use [53] and previous qualitative research [54-58], dimensions and variables were identified. In addition, systematic reviews were conducted of studies on access and equity of access to health care and of available tools in order to identify additional variables. The literature search was carried out using the most relevant electronic databases (Pubmed, CINAHL, Social Science Citation Index, PsycInfo, Lilacs, IBECS, The Cochrane Library, System for Information on Grey Literature in Europe, Information system of the WHO Library, Panamerican Health Organization Library) to minimize the likelihood of excluding relevant studies. The search strategy included the combination of descriptors and keywords relating to equity in access to health care, delivery of health care and measurement instruments, utilizing the Boolean operator 'AND'. Given the large number of 
studies identified, only studies from Colombia, Brazil, United States and Spain were included. The U.S. and Spain were included because their health systems are comparable to the Colombian and Brazilian system respectively. A total of 41 different articles were identified up to 2010. Based on these results, the first version of the questionnaire was built and validated by means of discussions with experts, after which it was adapted to both context and languages. A pre-test and a pilot test were conducted in each country to evaluate the rhythm of the interview, interviewer burden and comprehensibility. Both the rhythm of the interview and the interviewer burden proved adequate. With respect to comprehensibility, some questions were removed and others modified because the terms used were unfamiliar and people had problems understanding them. Finally, since many changes had been made, another pilot was deemed necessary, in which the questionnaire was finally considered to be adequate. The final questionnaire is divided into nine sections. The first collects information on perceived health needs and related behavior in the three months prior to the survey, in other words, whether or not the individual had used the health services and the level of care at which they had been attended. The next four sections refer to their most recent experience - within the three months prior to the survey using the different levels of health care (primary, outpatient secondary, emergency, and inpatient care) of the SGSSS and SUS services. The last three sections include a Likert scale to measure care continuity, knowledge of the healthcare system and sociodemographic data. The Colombian questionnaire has an additional section related to insurance enrollment.

\section{Data collection}

Data were collected from February to June 2011 by means of face-to-face interviews conducted by specifically trained interviewers in both countries.

Strategies to ensure the quality and consistency of data included close supervision of interviewers in the field, the review of all questionnaires and $20 \%$ of re-interviews (selected randomly). Inconsistencies during data entry were controlled through the double-entry method.

\section{Ethical considerations}

Ethics approval was obtained from the ethics committees in the participating countries: the National Committee of Research Ethics in Brazil; the Research Ethics Committee of the Health Sciences School of Universidad del Rosario in Colombia; the Institutional Review Board of the Institute of Tropical Medicine in Belgium; and the Clinical Research Ethics Committee of Parc de Salut Mar in Spain. All interviewees participated on a voluntary basis, after signing an informed consent. The right to refuse to participate or withdraw from the survey, anonymity, confidentiality and protection of data were all guaranteed.

\section{Variables}

The outcome variables are three dichotomous variables on utilization of healthcare services in the three months prior to the survey: a) consultation of a general practitioner or pediatrician, b) consultation of a specialist, c) consultation of emergency care services; and three variables on the use of preventive services by adults in the last year: d) glycemic control, e) caries prevention and f) mammography in women.

Need for care was measured by self-rated health (dichotomous: i) good - very good and good, and ii) poor fair, poor and very poor) and having at least one chronic condition [59]. The main explanatory variables were per capita income and holding a private health plan in both countries as a proxy of socio-economic status, and type of SGSSS insurance scheme in Colombia. Per capita income (less than half minimum wage (MW), $1 / 2-1 \mathrm{MW}$, 2 or more MWs) was estimated by dividing the household income by the family size. Sociodemographic variables - sex, age $(0-17,18-40,41-65,66$ or over) and race/color- were used to adjust the models.

\section{Data analysis}

A univariate analysis was performed to describe the distribution of the outcome and explanatory variables for each country (Table 1). To establish the relative association between each healthcare utilization variable and socioeconomic status, prevalence ratios (PR) and their corresponding 95\% confidence intervals were computed by means of Poisson regression models with robust variance (Tables 2 and 3). PR was considered better suited to our study than other measures of inequality such as the Relative Index of Inequality (RII) because the socioeconomic variables included in the models are not strictly hierarchical [60]. Absolute differences in utilization prevalence at both extremes of the three socioeconomic variables were also calculated. Both absolute and relative measures were used to assess socioeconomic inequalities in the utilization of healthcare services.

In addition, stratified analyses were carried out: firstly, regression models were generated stratifying by income to evaluate the effect of the insurance scheme in Colombia and additional private health insurance in Brazil on health services utilization for each socioeconomic stratum (Tables 4 and 5); and secondly, regression models were made stratifying by type of insurance in both countries (contributory and subsidized in Colombia, and only SUS or SUS and private health plan in Brazil) (Table 6). Analyses were carried out with STATA statistical package version 12 [61]. 
Table 1 Sociodemographic characteristics and perceived health care need of the study sample, in the study areas of Colombia and Brazil (2011)

\begin{tabular}{|c|c|c|c|c|}
\hline & \multicolumn{2}{|c|}{ Colombia $(n=2,163)$} & \multicolumn{2}{|c|}{ Brazil $(n=2,155)$} \\
\hline & $\mathrm{n}$ & $\%$ & $\mathrm{n}$ & $\%$ \\
\hline \multicolumn{5}{|l|}{ Sex } \\
\hline Male & 691 & 31.9 & 626 & 29.0 \\
\hline Female & 1,472 & 68.1 & 1,529 & 71.0 \\
\hline \multicolumn{5}{|l|}{ Age } \\
\hline $0-17$ & 300 & 13.9 & 483 & 22.4 \\
\hline $18-40$ & 667 & 30.8 & 497 & 23.1 \\
\hline $41-65$ & 909 & 42.0 & 766 & 35.6 \\
\hline$>65$ & 287 & 13.3 & 409 & 19.0 \\
\hline \multicolumn{5}{|l|}{ Level of education } \\
\hline None & 344 & 16.0 & 623 & 29.5 \\
\hline Primary & 804 & 37.4 & 583 & 27.6 \\
\hline Secondary & 821 & 38.2 & 798 & 37.8 \\
\hline University & 180 & 8.4 & 106 & 5.0 \\
\hline \multicolumn{5}{|l|}{ Per capita income } \\
\hline$<1 / 2 \mathrm{MW}$ & 951 & 44.0 & 1,121 & 52.0 \\
\hline $1 / 2-1 \mathrm{MW}$ & 775 & 35.8 & 720 & 33.4 \\
\hline$>1 \mathrm{MW}$ & 437 & 20.2 & 314 & 14.6 \\
\hline \multicolumn{5}{|l|}{ Private health plan } \\
\hline Yes & 42 & 2.0 & 434 & 20.1 \\
\hline No & 2,024 & 98.0 & 1,721 & 79.9 \\
\hline \multicolumn{5}{|l|}{ SGSSS scheme } \\
\hline Contributory & 1,144 & 56.0 & & \\
\hline Subsidized & 574 & 28.0 & & \\
\hline Special & 97 & 4.8 & & \\
\hline Uninsured & 231 & 11.3 & & \\
\hline \multicolumn{5}{|c|}{ Self-rated health status } \\
\hline Good & 1,346 & 62.3 & 962 & 44.7 \\
\hline Poor & 816 & 37.7 & 1,192 & 55.3 \\
\hline \multicolumn{5}{|l|}{ Chronic condition } \\
\hline Yes (at least one) & 650 & 30.0 & 903 & 41.9 \\
\hline No & 1,513 & 70.0 & 1,252 & 58.1 \\
\hline
\end{tabular}

MW, minimum wage; SGSSS, General System of Social Security in Health.

\section{Results}

Colombia and Brazil are used here to refer to the study areas even though the results are not extrapolated at country level.

\section{Sample characteristics}

In both samples, the majority of participants are women, and while in the Colombia sample there is a predominance of the central age groups (18 to 40 and 41 to 65 years), in that of Brazil there is a more even distribution of the sample across all age groups. With regard to
SGSSS enrollment, $56.0 \%$ are enrolled in the contributory scheme, $28.0 \%$ in the subsidized scheme, and $11.3 \%$ are uninsured. The socioeconomic status of the sample is not very high in either country: most people have less than half of the minimum wage (MW) per month, but distribution is less equal in Brazil than in Colombia. The socioeconomic level in Colombia is closely related to enrollment; the proportion of people with less than half MW in the previous month is higher in the subsidized scheme and the uninsured group than in the contributory scheme: $72.0 \%, 63.2 \%$ and $36.4 \%$ respectively. In Colombia 2.0\% and in Brazil 20.1\% hold a private health plan (PHP) (Table 1). Self-rated health status is better in Colombia: $62.2 \%$ report good or very good health, compared to $44.7 \%$ in Brazil; $30.0 \%$ claim to have at least one chronic disease, as opposed to $41.9 \%$ in Brazil (Table 1).

\section{Use of health care services}

In the Colombia sample more than half of the individuals used the first level of care (52.2\%), a higher proportion than in that of Brazil (44.5\%). However, for outpatient secondary and emergency care, utilization in Brazil was significantly higher than in Colombia (Figure 1). Preventive activities in the last year differ between countries according to type of activity: while the proportions of people who used glycemic control and mammography services were similar, significant differences were found in caries prevention in adults $(37.7 \%$ in Colombia vs. $19.9 \%$ in Brazil) (Figure 1).

\section{Differences in socioeconomic-related inequalities in health services utilization}

At primary care level, per capita income does not figure as a source of inequality in Colombia but it does in Brazil, where individuals with a higher per capita income make less use of this care level (prevalence difference with respect to the poorest is $-17.9, \mathrm{PR}=0.71, \mathrm{CI} 95 \%$ : 0.59-0.85). In Colombia, it is the insurance scheme which is associated with the utilization of services at this level. The utilization prevalence of individuals in the contributory scheme is $58.0 \%$, in the subsidized scheme $52.1 \%$, and $24.7 \%$ for the uninsured (Table 2). In outpatient secondary care, per capita income is a source of inequity in both countries: higher-income individuals are more likely to use these services. In Colombia, the PR of individuals with more than one minimum wage per capita to those with the lowest income is 1.26 (CI 95\%: 1.02-1.56) and in Brazil, 1.42 (CI 95\%: 1.14-1.77), which is the opposite pattern of use to that detected at primary care level. Holding a private health plan is also associated with a higher prevalence of utilization in both countries. Furthermore, in Colombia, insurance enrollment reveals the same pattern as that found in primary 
Table 2 Prevalence, prevalence difference and prevalence ratios (95\% confidence intervals) of health services utilization in the last three months by per capita income, SGSSS insurance scheme and private health plan, in the study areas of Colombia and Brazil (2011)

\begin{tabular}{|c|c|c|c|c|c|c|c|c|}
\hline & \multicolumn{4}{|c|}{ Colombia } & \multicolumn{4}{|c|}{ Brazil } \\
\hline & $\mathbf{n}$ & Prev. & PD & PR $\left(\mathrm{Cl}\right.$ 95\%) ${ }^{\mathrm{a}}$ & $\mathbf{n}$ & Prev. & PD & PR $(C l \text { 95\%) })^{a}$ \\
\hline \multicolumn{9}{|l|}{ Primary care } \\
\hline \multicolumn{9}{|l|}{ Per capita income } \\
\hline$<1 / 2 \mathrm{MW}$ & 473 & 49.8 & & 1 & 550 & 49.1 & & 1 \\
\hline $1 / 2-1 \mathrm{MW}$ & 409 & 52.8 & 3.0 & $1.04(0.94-1.14)$ & 310 & 43.1 & -6.0 & $0.89(0.80-0.99)$ \\
\hline$>1 \mathrm{MW}$ & 246 & 56.4 & 6.6 & $1.01(0.91-1.13)$ & 98 & 31.2 & -17.9 & $0.71(0.59-0.85)$ \\
\hline \multicolumn{9}{|l|}{ SGSSS scheme } \\
\hline Contributory + special & 718 & 58.0 & & 1 & & & & \\
\hline Subsidized & 298 & 52.1 & -5.9 & $0.90(0.81-0.99)$ & & & & \\
\hline Uninsured & 57 & 24.7 & -33.3 & $0.46(0.37-0.58)$ & & & & \\
\hline \multicolumn{9}{|l|}{ Private Health Plan } \\
\hline No & 1,041 & 51.5 & & 1 & 800 & 46.5 & & 1 \\
\hline Yes & 27 & 64.3 & 12.8 & $1.13(0.90-1.41)$ & 158 & 36.4 & -10.1 & $0.91(0.79-1.05)$ \\
\hline \multicolumn{9}{|l|}{ Outpatient secondary care } \\
\hline \multicolumn{9}{|l|}{ Per capita income } \\
\hline$<1 / 2 \mathrm{MW}$ & 160 & 16.9 & & 1 & 228 & 20.3 & & 1 \\
\hline $1 / 2-1 \mathrm{MW}$ & 150 & 19.4 & 2.5 & $1.02(0.83-1.26)$ & 200 & 27.8 & 7.5 & $1.26(1.07-1.48)$ \\
\hline$>1 \mathrm{MW}$ & 118 & 27.1 & 10.2 & $1.26(1.02-1.56)$ & 96 & 30.6 & 10.3 & $1.42(1.14-1.77)$ \\
\hline \multicolumn{9}{|l|}{ SGSSS scheme } \\
\hline Contributory + special & 300 & 24.2 & & 1 & & & & \\
\hline Subsidized & 93 & 16.3 & -7.9 & $0.72(0.57-0.90)$ & & & & \\
\hline Uninsured & 17 & 7.4 & -16.8 & $0.40(0.25-0.64)$ & & & & \\
\hline \multicolumn{9}{|l|}{ Private Health Plan } \\
\hline No & 393 & 19.5 & & 1 & 391 & 22.7 & & 1 \\
\hline Yes & 16 & 38.1 & 18.6 & $1.74(1.14-2.66)$ & 133 & 30.7 & 8.0 & $1.40(1.18-1.67)$ \\
\hline \multicolumn{9}{|l|}{ Emergency care } \\
\hline \multicolumn{9}{|l|}{ Per capita income } \\
\hline$<1 / 2 \mathrm{MW}$ & 192 & 20.2 & & 1 & 390 & 34.8 & & 1 \\
\hline $1 / 2-1 \mathrm{MW}$ & 141 & 18.2 & -2.0 & $1.14(0.92-1.41)$ & 240 & 33.3 & -1.5 & $1.09(0.95-1.25)$ \\
\hline$>1 \mathrm{MW}$ & 70 & 16.1 & -4.1 & $0.98(0.74-1.29)$ & 74 & 23.6 & -11.2 & $0.88(0.70-1.11)$ \\
\hline \multicolumn{9}{|l|}{ SGSSS scheme } \\
\hline Contributory + special & 230 & 18.6 & & 1 & & & & \\
\hline Subsidized & 123 & 21.5 & 2.9 & $0.94(0.76-1.17)$ & & & & \\
\hline Uninsured & 33 & 14.3 & -4.3 & $0.63(0.45-0.88)$ & & & & \\
\hline \multicolumn{9}{|l|}{ Private Health Plan } \\
\hline No & 371 & 18.4 & & 1 & 579 & 33.6 & & 1 \\
\hline Yes & 12 & 28.6 & 10.2 & $1.75(1.06-2.86)$ & 125 & 28.8 & -4.8 & $0.93(0.78-1.11)$ \\
\hline
\end{tabular}

Prev, Prevalence; PD, Prevalence Difference; PR, Prevalence ratio; Cl, Confidence Interval; MW, minimum wage; SGSSS, General System of Social Security in Health. ${ }^{a}$ Prevalence Ratio and 95\% confidence interval adjusted for sex, age, race/color, chronic condition, self-rated health status.

Statistically significant results are shown in bold.

care. Individuals in the contributory scheme display the highest use of this care level: the PR of subsidized to contributory is 0.72 (CI 95\%: 0.57-0.90) and of uninsured to contributory is 0.40 (CI 95\%; 0.24-0.64) (Table 2). With regard to emergency care services, the higher the per capita income is, the lower the prevalence of utilization in both 
Table 3 Prevalence, prevalence difference and prevalence ratios ( $95 \%$ confidence intervals) of preventive care activities in the last year by per capita income, SGSSS insurance scheme and private health plan, in the study areas of Colombia and Brazil (2011)

\begin{tabular}{|c|c|c|c|c|c|c|c|c|}
\hline & \multicolumn{4}{|c|}{ Colombia } & \multicolumn{4}{|c|}{ Brazil } \\
\hline & $\mathbf{n}$ & Prev & PD & PR $(C l \text { 95\%) })^{a}$ & $\mathbf{n}$ & Prev & PD & PR $(C l \text { 95\%) })^{a}$ \\
\hline \multicolumn{9}{|l|}{ Glycemic control (adults) } \\
\hline \multicolumn{9}{|l|}{ Per capita income } \\
\hline$<1 / 2 \mathrm{MW}$ & 441 & 49.8 & & 1 & 427 & 52.6 & & 1 \\
\hline $1 / 2-1 \mathrm{MW}$ & 275 & 47.5 & -2.3 & $0.97(0.87-1.08)$ & 346 & 58.8 & 6.2 & $1.11(1.01-1.21)$ \\
\hline$>1 \mathrm{MW}$ & 230 & 57.6 & 7.8 & $1.09(0.98-1.22)$ & 160 & 58.8 & 6.2 & $1.11(0.98-1.26)$ \\
\hline \multicolumn{9}{|l|}{ SGSSS scheme } \\
\hline Contributory + special & 626 & 56.6 & & 1 & & & & \\
\hline Subsidized & 223 & 47.8 & -8.8 & $0.83(0.75-0.93)$ & & & & \\
\hline Uninsured & 54 & 28.3 & -28.3 & $0.59(0.47-0.75)$ & & & & \\
\hline \multicolumn{9}{|l|}{ Private Health Plan } \\
\hline No & 890 & 50.9 & & 1 & 726 & 53.6 & & 1 \\
\hline Yes & 19 & 54.3 & 3.4 & $0.98(0.73-1.33)$ & 207 & 65.1 & 11.5 & $1.26(1.14-1.40)$ \\
\hline \multicolumn{9}{|l|}{ Caries prevention (adults) } \\
\hline \multicolumn{9}{|l|}{ Per capita income } \\
\hline$<1 / 2 \mathrm{MW}$ & 308 & 34.8 & & 1 & 123 & 15.2 & & 1 \\
\hline $1 / 2-1 \mathrm{MW}$ & 232 & 40.1 & 5.3 & $1.13(0.98-1.30)$ & 129 & 21.9 & 6.7 & $1.34(1.07-1.67)$ \\
\hline$>1 \mathrm{MW}$ & 162 & 40.6 & 5.8 & $1.12(0.94-1.32)$ & 81 & 29.8 & 14.6 & $1.41(1.08-1.84)$ \\
\hline \multicolumn{9}{|l|}{ SGSSS scheme } \\
\hline Contributory + special & 437 & 39.5 & & 1 & & & & \\
\hline Subsidized & 172 & 36.8 & -2.7 & $0.95(0.81-1.11)$ & & & & \\
\hline Uninsured & 59 & 30.9 & -8.6 & $0.75(0.60-0.94)$ & & & & \\
\hline \multicolumn{9}{|l|}{ Private Health Plan } \\
\hline No & 658 & 37.6 & & 1 & 218 & 16.1 & & 1 \\
\hline Yes & 15 & 42.9 & 5.3 & $1.15(0.80-1.65)$ & 115 & 36.2 & 20.1 & $1.86(1.52-2.28)$ \\
\hline \multicolumn{9}{|c|}{ Breast cancer prevention (women) } \\
\hline \multicolumn{9}{|l|}{ Per capita income } \\
\hline$<1 / 2 \mathrm{MW}$ & 144 & 21.9 & & 1 & 168 & 26.3 & & 1 \\
\hline $1 / 2-1 \mathrm{MW}$ & 120 & 30.0 & 8.1 & $1.27(1.04-1.57)$ & 128 & 27.9 & 1.6 & $1.10(0.90-1.33)$ \\
\hline$>1 \mathrm{MW}$ & 96 & 37.2 & 15.3 & $1.37(1.10-1.71)$ & 69 & 37.3 & 11.0 & $1.47(1.14-1.90)$ \\
\hline \multicolumn{9}{|l|}{ SGSSS scheme } \\
\hline Contributory + special & 261 & 34.7 & & 1 & & & & \\
\hline Subsidized & 63 & 17.8 & -16.9 & $0.59(0.46-0.76)$ & & & & \\
\hline Uninsured & 15 & 11.0 & -23.7 & $0.43(0.27-0.70)$ & & & & \\
\hline \multicolumn{9}{|l|}{ Private Health Plan } \\
\hline No & 344 & 27.8 & & 1 & 276 & 26.5 & & 1 \\
\hline Yes & 9 & 36.0 & 8.2 & $0.99(0.58-1.67)$ & 89 & 36.8 & 10.3 & $1.38(1.11-1.70)$ \\
\hline
\end{tabular}

Prev, Prevalence; PD, Prevalence Difference; PR, Prevalence ratio; Cl, Confidence Interval; MW, minimum wage; SGSSS, General System of Social Security in Health. ${ }^{a}$ Prevalence Ratio and 95\% confidence interval adjusted for sex, age, race/color, chronic condition, self-rated health status.

Statistically significant results are shown in bold.

countries, although once this is adjusted for need there are no perceivable inequities associated with income and private insurance in either country. However, in Colombia individuals not insured under the SGSSS are unfavorably positioned with respect to those insured under the contributory scheme (PR: 0.63, CI 95\% 0.45-0.88) (Table 2). 
Table 4 Prevalence, prevalence difference and prevalence ratios (95\% confidence intervals) of health services utilization in the last three months and of preventive activities in the last year by SGSSS insurance scheme, according to per capita income, in the study areas of Colombia (2011)

\begin{tabular}{|c|c|c|c|c|c|c|c|c|c|c|c|c|}
\hline & \multicolumn{4}{|c|}{$<1 / 2$ MW (per capita) } & \multicolumn{4}{|c|}{$1 / 2-1$ MW (per capita) } & \multicolumn{4}{|c|}{ > 1 MW (per capita) } \\
\hline & $n$ & Prev & PD & PR (Cl 95\%) $)^{a}$ & $\mathrm{n}$ & Prev & PD & PR (Cl 95\%) $)^{a}$ & $\mathrm{n}$ & Prev & PD & PR (CI 95\%) ${ }^{a}$ \\
\hline \multicolumn{13}{|l|}{ Primary care } \\
\hline Contributory + special & 261 & 57.9 & & 1 & 243 & 58.0 & & 1 & 214 & 58.0 & & 1 \\
\hline Subsidized & 210 & 51.0 & -6.9 & $0.88(0.78-1.01)$ & 70 & 54.7 & -3.3 & $0.92(0.77-1.10)$ & 18 & 56.3 & -1.7 & $0.91(0.65-1.29)$ \\
\hline Uninsured & 37 & 25.3 & -32.6 & $0.48(0.35-0.64)$ & 14 & 20.9 & -37.1 & $0.41(0.26-0.65)$ & 6 & 33.3 & -24.7 & $0.59(0.31-1.13)$ \\
\hline \multicolumn{13}{|c|}{ Outpatient secondary care } \\
\hline \multicolumn{13}{|l|}{ SGSSS scheme } \\
\hline Contributory + special & 105 & 23.3 & & 1 & 89 & 21.2 & & 1 & 106 & 28.7 & & 1 \\
\hline Subsidized & 65 & 15.8 & -7.5 & $0.70(0.53-0.94)$ & 19 & 14.8 & -6.4 & $0.59(0.38-0.91)$ & 9 & 28.1 & -0.6 & $1.16(0.66-2.05)$ \\
\hline Uninsured & 12 & 8.2 & -15.1 & $0.45(0.25-0.81)$ & 5 & 7.5 & -13.7 & $0.38(0.16-0.88)$ & 0 & 0 & - & - \\
\hline \multicolumn{13}{|l|}{ Emergency care } \\
\hline Contributory + special & 87 & 19.3 & & 1 & 84 & 20.1 & & 1 & 59 & 16.0 & & 1 \\
\hline Subsidized & 91 & 22.1 & 2.8 & $0.92(0.70-1.21)$ & 28 & 21.9 & 1.8 & $1.04(0.71-1.54)$ & 4 & 12.5 & -3.7 & $0.60(0.21-1.70)$ \\
\hline Uninsured & 23 & 15.8 & -3.5 & $0.67(0.44-1.01)$ & 7 & 10.5 & -9.6 & $0.52(0.26-1.05)$ & 3 & 16.7 & 0.7 & $0.97(0.37-2.57)$ \\
\hline \multicolumn{13}{|l|}{ Glycemic control (adults) } \\
\hline Contributory + special & 230 & 58.4 & & 1 & 188 & 50.4 & & 1 & 208 & 61.4 & & 1 \\
\hline Subsidized & 152 & 46.9 & -11.5 & $0.80(0.69-0.92)$ & 57 & 50.0 & -0.4 & $0.90(0.74-1.10)$ & 14 & 48.3 & -13.1 & $0.83(0.57-1.23)$ \\
\hline Uninsured & 33 & 29.0 & -29.4 & $0.61(0.45-0.82)$ & 19 & 31.7 & -18.7 & $0.70(0.48-1.04)$ & 2 & 11.8 & -49.6 & $0.23(\mathbf{0 . 0 6}-\mathbf{0 . 8 2})$ \\
\hline \multicolumn{13}{|l|}{ Caries prevention (adults) } \\
\hline Contributory + special & 149 & 37.8 & & 1 & 149 & 40.0 & & 1 & 139 & 41.0 & & 1 \\
\hline Subsidized & 108 & 33.3 & -4.5 & $0.83(0.67-1.03)$ & 51 & 44.7 & 4.7 & $1.13(0.89-1.44)$ & 13 & 44.8 & 3.8 & $1.06(0.68-1.64)$ \\
\hline Uninsured & 32 & 28.1 & -9.7 & $0.70(0.51-0.97)$ & 22 & 36.7 & -3.3 & $0.84(0.58-1.20)$ & 5 & 29.4 & -11.6 & $0.64(0.30-1.33)$ \\
\hline \multicolumn{13}{|c|}{ Breast cancer prevention (women) } \\
\hline Contributory + special & 88 & 31.3 & & 1 & 86 & 33.6 & & & 87 & 40.5 & & 1 \\
\hline Subsidized & 32 & 12.8 & -18.5 & $0.46(0.31-0.66)$ & 25 & 31.3 & -2.3 & $0.82(0.57-1.16)$ & 6 & 26.1 & -14.4 & $0.68(0.35-1.34)$ \\
\hline Uninsured & 9 & 10.5 & -20.8 & $0.48(0.26-0.88)$ & 5 & 12.8 & -20.8 & $0.42(0.18-1.00)$ & 1 & 8.3 & -32.2 & $0.28(0.04-2.03)$ \\
\hline
\end{tabular}

Prev, Prevalence; PD, Prevalence Difference; PR, Prevalence ratio; Cl, Confidence Interval; MW, minimum wage; SGSSS, General System of Social Security in Health.

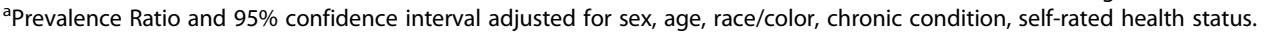

Statistically significant results are shown in bold.

There are noticeable inequities in preventive activities in both countries. The absolute differences in utilization prevalence (of all three socioeconomic variables) are always in favor of those who are most socioeconomically favored. In Colombia, uninsured individuals are less likely to use the three preventive services than those of the contributory scheme. Moreover, individuals in the subsidized scheme are less likely to have glycemic controls and mammographies than individuals in the contributory scheme. The inequities are accentuated in breast cancer prevention according to per capita income: the prevalence of utilization increases as the level of income rises (21.9\%, 30.0\% and 37.2\%). In Brazil, people with a lower income and without private insurance are less likely to use the three preventive services, and the difference in prevalence of using caries prevention services is particularly marked between those without private insurance (16.1\%) and those with (36.2\%) (Table 3).

\section{What are the effects of type of SGSSS insurance scheme} and private health plan at each level of income?

This second section looks closely at the effects in each income stratum of insurance scheme in Colombia and holding a private health plan in Brazil on the utilization of healthcare services, after having observed an association between higher socioeconomic status and greater use of the health services. In Colombia, in the two lower-income strata, individuals of the contributory scheme are more likely to use the primary and outpatient secondary care services than the uninsured; and they are also more likely to use outpatient secondary care than individuals in the subsidized scheme $(\mathrm{PR}=$ 
Table 5 Prevalence, prevalence difference and prevalence ratios (95\% confidence intervals) of health services utilization in the last three months and of preventive activities in the last year by private health plan (PHP), according to per capita income, in the study areas of Brazil (2011)

\begin{tabular}{|c|c|c|c|c|c|c|c|c|c|c|c|c|}
\hline & \multicolumn{4}{|c|}{$<1 / 2$ MW (per capita) } & \multicolumn{4}{|c|}{$1 / 2-1$ MW (per capita) } & \multicolumn{4}{|c|}{ > 1 MW (per capita) } \\
\hline & $\mathrm{n}$ & Prev & PD & PR (Cl 95\%) $)^{a}$ & $\mathrm{n}$ & Prev & PD & PR (Cl 95\%) $)^{a}$ & $\bar{n}$ & Prev & PD & PR (Cl 95\%) $)^{a}$ \\
\hline \multicolumn{13}{|l|}{ Primary care } \\
\hline Without PHP & 506 & 49.3 & & 1 & 247 & 45.2 & & 1 & 47 & 32.0 & & 1 \\
\hline With PHP & 44 & 46.8 & -2.5 & $0.99(0.79-1.25)$ & 63 & 36.4 & -8.8 & $0.79(0.64-0.99)$ & 51 & 30.5 & -1.5 & $0.95(0.68-1.33)$ \\
\hline \multicolumn{13}{|c|}{ Outpatient secondary care } \\
\hline Without PHP & 212 & 20.6 & & 1 & 141 & 25.8 & & 1 & 38 & 25.9 & & 1 \\
\hline With PHP & 16 & 17.0 & -3.6 & $0.98(0.64-1.52)$ & 59 & 34.1 & 8.3 & $1.57(1.23-2.00)$ & 58 & 34.7 & 8.8 & $1.40(1.02-1.93)$ \\
\hline \multicolumn{13}{|l|}{ Emergency care } \\
\hline Without PHP & 348 & 33.9 & & 1 & 194 & 35.5 & & 1 & 37 & 25.2 & & 1 \\
\hline With PHP & 42 & 44.7 & 10.8 & $1.35(1.05-1.72)$ & 46 & 26.6 & -8.9 & $0.66(0.50-0.86)$ & 37 & 22.2 & -3.0 & $1.03(0.68-1.55)$ \\
\hline \multicolumn{13}{|c|}{ Glycemic control (adults) } \\
\hline Without PHP & 391 & 52.1 & & 1 & 268 & 57.0 & & 1 & 67 & 50.0 & & 1 \\
\hline With PHP & 36 & 58.1 & 6.0 & $1.16(0.93-1.45)$ & 78 & 66.1 & 9.1 & $1.22(1.06-1.42)$ & 93 & 67.4 & 17.4 & $1.40(1.15-1.71)$ \\
\hline \multicolumn{13}{|c|}{ Caries prevention (adults) } \\
\hline Without PHP & 107 & 14.3 & & 1 & 88 & 18.7 & & 1 & 23 & 17.2 & & 1 \\
\hline With PHP & 16 & 25.8 & 11.5 & $1.80(1.15-2.82)$ & 41 & 34.8 & 16.1 & $1.58(1.17-2.12)$ & 58 & 42.0 & 24.8 & $2.42(1.59-3.68)$ \\
\hline \multicolumn{13}{|c|}{ Breast cancer prevention (women) } \\
\hline Without PHP & 149 & 25.3 & & 1 & 100 & 27.4 & & 1 & 27 & 31.0 & & 1 \\
\hline With PHP & 19 & 38.0 & 12.7 & $1.61(1.09-2.36)$ & 28 & 29.8 & 2.4 & $1.15(0.81-1.63)$ & 42 & 42.9 & 11.9 & $1.48(1.02-2.15)$ \\
\hline
\end{tabular}

Prev, Prevalence; PD, Prevalence Difference; PR, Prevalence ratio; $\mathrm{Cl}$, Confidence Interval; MW, minimum wage; PHP, Private Health Plan.

${ }^{a}$ Prevalence Ratio and $95 \%$ confidence interval adjusted for sex, age, race/color, chronic condition, self-rated health status.

Statistically significant results are shown in bold.

0.70, CI 95\% 0.53-0.94 in the lower per capita income stratum and PR=0.59, CI 95\%: $0.38-0.91$ in the middle stratum). Inequalities between schemes were not found in the case of emergency care (Table 4). The effect of the insurance scheme on the use of preventive services is particularly noticeable in the lowest per capita income stratum, where belonging to the subsidized scheme or being uninsured significantly reduces the probability of using glycemic control services (prevalence difference between individuals in the contributory scheme and in the subsidized scheme is -11.5 , and between individuals in the contributory scheme and the uninsured is -29.4) and mammography services (prevalence difference is -18.5 for the subsidized enrollees and -20.8 for the uninsured) (Table 4).

In the case of Brazil, the effect of private insurance varies depending on care level and income. It is most influential in the middle-income stratum, where individuals with a private health plan are less likely to use primary and emergency care services and more likely to use outpatient secondary care: the PR of those with insurance to those without is 1.57 (CI 95\% 1.23-2.00) (Table 5). Having a private health plan implies a greater likelihood of using the three preventive services in all income strata (Table 5).
What are the effects of income on each health subsystem?

Lastly, the presence of inequities was evaluated according to insurance scheme in Colombia and type of coverage in Brazil (Table 6). In Colombia, the prevalence values for services utilization are consistently higher in the contributory scheme than in the subsidized scheme in all income strata, with the exception of emergency care and caries prevention. In the contributory scheme, level of income does not reveal inequity in health services utilization, except in the cases of outpatient secondary care and breast cancer prevention, which are used more frequently among higher income individuals. In the subsidized scheme, no inequity was detected according to level of income in use of the curative services, but it was observed in the preventive services such as caries prevention (PR comparing those in the middle income stratum with those in the lower is 1.45 , CI 95\%: 1.12 - 1.87) and breast cancer prevention $(\mathrm{PR}=2.00$, CI 95\%: 1.28 - 3.11) (Table 6). This analysis could not be performed in the uninsured group due to its low level of use of the health services.

In Brazil, higher-income individuals are less likely to use the primary care level whether they hold a private 
Table 6 Prevalence, prevalence difference and prevalence ratios (95\% confidence intervals) of health services utilization in the last three months and of preventive activities in the last year by per capita income according to SGSSS insurance scheme and private health plan, in the study areas of Colombia and Brazil (2011)

\begin{tabular}{|c|c|c|c|c|c|c|c|c|c|c|c|c|c|c|c|c|}
\hline & \multicolumn{8}{|c|}{ Colombia } & \multicolumn{8}{|c|}{ Brazil } \\
\hline & \multicolumn{4}{|c|}{ Contributory scheme } & \multicolumn{4}{|c|}{ Subsidized scheme } & \multicolumn{4}{|c|}{ Without private health plan } & \multicolumn{4}{|c|}{ With private health plan } \\
\hline & $n$ & Prev & PD & PR (Cl 95\%) $)^{a}$ & $n$ & Prev & PD & PR (Cl 95\%) $)^{a}$ & $\mathrm{n}$ & Prev & PD & PR (Cl 95\%) & $\mathrm{n}$ & Prev & PD & PR (Cl 95\%) \\
\hline \multicolumn{17}{|l|}{ Primary care } \\
\hline$<1 / 2 \mathrm{MW}$ & 261 & 57.9 & & 1 & 210 & 51.0 & & 1 & 506 & 49.3 & & 1 & 44 & 46.8 & & 1 \\
\hline $1 / 2-1 \mathrm{MW}$ & 243 & 58.0 & 0.1 & $1.05(0.94-1.17)$ & 70 & 54.7 & 3.7 & $1.08(0.90-1.29)$ & 247 & 45.2 & -4.1 & $0.91(0.81-1.02)$ & 63 & 36.4 & -10.4 & $0.75(0.56-1.02)$ \\
\hline$>1 \mathrm{MW}$ & 214 & 58.0 & 0.1 & $1.03(0.92-1.16)$ & 18 & 56.3 & 5.3 & $1.07(0.78-1.48)$ & 47 & 32.0 & -17.3 & $0.69(0.54-0.88)$ & 51 & 30.5 & -16.3 & $0.66(0.48-0.93)$ \\
\hline \multicolumn{17}{|c|}{ Outpatient secondary care } \\
\hline$<1 / 2 \mathrm{MW}$ & 105 & 23.3 & & 1 & 65 & 15.8 & & 1 & 212 & 20.6 & & 1 & 16 & 17.0 & & 1 \\
\hline $1 / 2-1 \mathrm{MW}$ & 89 & 21.2 & -2.1 & $1.02(0.80-1.29)$ & 19 & 14.8 & -1.0 & $0.87(0.55-1.39)$ & 141 & 25.8 & 5.2 & $1.17(0.98-1.41)$ & 59 & 34.1 & 17.1 & $1.94(1.22-3.10)$ \\
\hline$>1 \mathrm{MW}$ & 106 & 28.7 & 5.4 & $1.26(1.01-1.58)$ & 9 & 28.1 & 12.3 & $1.72(0.98-3.02)$ & 38 & 25.9 & 5.3 & $1.34(1.00-1.79)$ & 58 & 34.7 & 17.7 & $1.98(1.23-3.20)$ \\
\hline \multicolumn{17}{|c|}{ Emergency care } \\
\hline$<1 / 2 \mathrm{MW}$ & 87 & 19.3 & & 1 & 91 & 22.1 & & 1 & 348 & 33.9 & & 1 & 42 & 44.7 & & 1 \\
\hline $1 / 2-1 \mathrm{MW}$ & 84 & 20.1 & 0.8 & $1.11(0.85-1.45)$ & 28 & 21.9 & -0.2 & $1.19(0.82-1.73)$ & 194 & 35.5 & 1.6 & $1.19(1.04-1.38)$ & 46 & 26.6 & -18.1 & $0.63(0.45-0.87)$ \\
\hline$>1 \mathrm{MW}$ & 59 & 16.0 & -3.3 & $0.95(0.70-1.29)$ & 4 & 12.5 & -9.6 & $0.72(0.29-1.75)$ & 37 & 25.2 & -8.7 & $0.90(0.67-1.22)$ & 37 & 22.2 & -22.5 & $0.70(0.48-1.01)$ \\
\hline \multicolumn{17}{|c|}{ Glycemic control (adults) } \\
\hline$<1 / 2 \mathrm{MW}$ & 230 & 58.4 & & 1 & 152 & 46.9 & & 1 & 391 & 52.1 & & 1 & 36 & 58.1 & & 1 \\
\hline $1 / 2-1 \mathrm{MW}$ & 188 & 50.4 & -8.0 & $0.93(0.82-1.05)$ & 57 & 50.0 & 3.1 & $1.07(0.87-1.31)$ & 268 & 57.0 & 4.9 & $1.11(1.00-1.23)$ & 78 & 66.1 & 8.0 & $1.15(0.90-1.47)$ \\
\hline$>1 \mathrm{MW}$ & 208 & 61.4 & 3.0 & $1.11(0.99-1.25)$ & 14 & 48.3 & 1.4 & $1.03(0.71-1.51)$ & 67 & 50.0 & -2.1 & $1.05(0.87-1.26)$ & 93 & 67.4 & 9.3 & $1.21(0.95-1.53)$ \\
\hline \multicolumn{17}{|c|}{ Caries prevention (adults) } \\
\hline$<1 / 2 \mathrm{MW}$ & 149 & 37.8 & & 1 & 108 & 33.3 & & 1 & 107 & 14.3 & & 1 & 16 & 25.8 & & 1 \\
\hline $1 / 2-1 \mathrm{MW}$ & 149 & 40.0 & 2.2 & $1.02(0.85-1.22)$ & 51 & 44.7 & 11.4 & $1.45(1.12-1.87)$ & 88 & 18.7 & 4.4 & $1.37(1.06-1.76)$ & 41 & 34.8 & 9.0 & $1.34(0.83-2.17)$ \\
\hline$>1 \mathrm{MW}$ & 139 & 41.0 & 3.2 & $1.06(0.88-1.27)$ & 13 & 44.8 & 11.5 & $1.45(0.97-2.16)$ & 23 & 17.2 & 2.9 & $1.11(0.73-1.69)$ & 58 & 42.0 & 16.2 & $1.87(1.16-3.01)$ \\
\hline \multicolumn{17}{|c|}{ Breast cancer prevention (women) } \\
\hline$<1 / 2 \mathrm{MW}$ & 88 & 31.3 & & 1 & 32 & 12.8 & & 1 & 149 & 25.3 & & 1 & 19 & 38.0 & & 1 \\
\hline $1 / 2-1 \mathrm{MW}$ & 86 & 33.6 & 2.3 & $1.13(0.89-1.42)$ & 25 & 31.3 & 18.5 & $2.00(1.28-3.11)$ & 100 & 27.4 & 2.1 & $1.20(0.97-1.47)$ & 28 & 29.8 & -8.2 & $0.77(0.48-1.23)$ \\
\hline$>1 \mathrm{MW}$ & 87 & 40.5 & 9.2 & $1.35(1.07-1.69)$ & 6 & 26.1 & 13.3 & $1.69(0.82-3.45)$ & 27 & 31.0 & 5.7 & $1.50(1.05-2.14)$ & 42 & 42.9 & 4.9 & $1.10(0.73-1.68)$ \\
\hline
\end{tabular}

Prev, Prevalence; PD, Prevalence Difference; PR, Prevalence ratio; Cl, Confidence Interval; MW, minimum wage.

a Prevalence Ratio and $95 \%$ confidence interval adjusted for sex, age, race/color, chronic condition, self-rated health status.

Statistically significant results are shown in bold. 


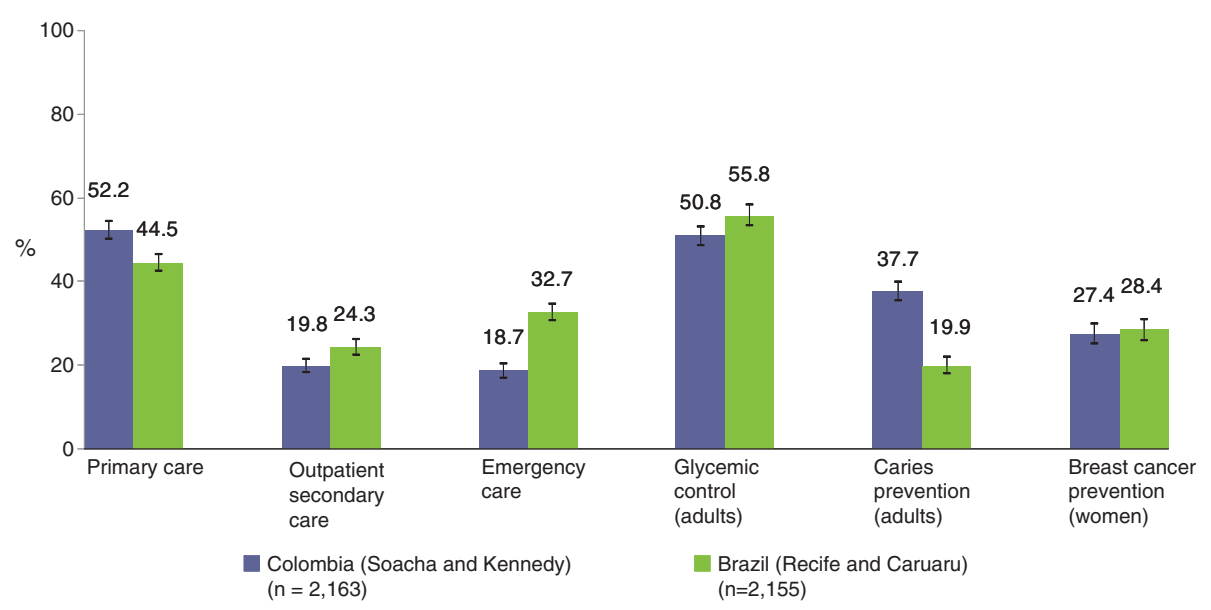

Figure 1 Prevalence of health services utilization in the last three months and of preventive care activities in the last year, study areas of Colombia and Brazil (2011).

health plan or not. In outpatient secondary care there is an income gradient in individuals with double coverage: the higher the income, the higher the probability of utilization ( $\mathrm{PR}=1.94$, CI 95\%: $1.22-3.10$ and $\mathrm{PR}=1.98$, CI 95\%; 1.23 - 3.20) (Table 6). The prevalence of use of preventive services are higher in the group with double coverage (SUS and PHP), and the relationship with income is significant in the case of caries prevention (in both groups), as well as in mammography in the group without private insurance (Table 6).

\section{Discussion}

Twenty years after the reforms implemented to improve equity in access to health care, in both countries inequities persist, in terms of an unequal use for equal need. Although caution should be exercised when drawing generalizations from its results, this study, conducted in two areas in the northeast of Brazil and two in central Colombia, reveals the presence of inequities according to per capita income, possession of a private health plan and SGSSS insurance scheme in the study areas analyzed, where a better socioeconomic status favors utilization of the health services.

In the Colombian areas inequities are found in favor of individuals of a higher socioeconomic status in the three care levels and in the use of preventive services; whereas in the Brazilian areas, the use of secondary services and preventive activities is unequal in favor of the higher-income population, and lower-income individuals make greater use of the primary care services.

In terms of the strengths of the study, we should highlight that this is a comparative analysis based on primary data and with a common questionnaire in which the questions and the recall period are identical, thus avoiding the methodological limitations of international studies based on secondary data which have arisen in other comparative articles [41]. It has therefore allowed us to compare the inequities in access in two countries with different health systems, as well as to fill a current gap in the literature with regard to inequities in the utilization of different care levels and preventive services.

The inequities found would have been greater if the general population had been the object of the study: firstly, due to the fact that the study was also oriented to analyzing barriers in access to the health services of the General System of Social Security in Health (SGSSS) and the Unified Health System (SUS) [62], so areas were selected in which the use of these was predominant over the use of private health services, in other words, areas in which there is a concentration of the low to middlelow income population; and secondly, because the study population was made up of individuals with some kind of health problem or a perceived healthcare need in the three months prior to the interview, and the perception of need for care is greater in the groups with the lowest socioeconomic status than in the general population.

\section{(In)equity in healthcare services utilization in Colombia}

One of the successes attributed to the Colombian reforms is an increase in the population enrolled in the SGSSS, as this was considered to facilitate access and use of the health services $[7,27,38]$. Although the uninsured population fell from $41.5 \%$ in 2000 to $12.1 \%$ in 2010 [15], there is a lack of consensus in the literature on the impact this has had on equity in utilization [39]. Our results coincide with those studies in which authors show that enrollment in the SGSSS improves access to the health services $[24,27,42]$, to the extent that uninsured individuals have practically no access. However, this study reveals that inequities also exist between the insurance schemes. Individuals of the subsidized scheme, with equal need, make the least use of primary, secondary and 
preventive care. This result is in contrast with those of other authors who conclude that enrollment guarantees access $[37,38]$, basing this conclusion on a utilization comparison between individuals of the subsidized scheme and the uninsured, without mentioning the differences between the two schemes. Furthermore these inequities are more pronounced in secondary care services, results which agree with the only study available that differentiates between the two care levels [7].

In emergency care, inequities between the two insurance schemes were not found, but they were found between the insured and uninsured, which appears to indicate that the legal obligation of all public and private entities to offer this type of care to everyone is not fulfilled [14], because it depends on the individual's insurance status.

It is interesting to note that the role of the insurance scheme is more evident among lower-income individuals, as in these strata it acts as a source of inequity in the utilization of preventive and curative services (with the exception of emergency care), whilst in the higherincome population no differences according to insurance scheme were found in the utilization of services. Moreover, no inequities according to income were found in individuals belonging to the same scheme. In other words, health services utilization by the poorest population - the one which has the greatest need for it - is determined by insurance scheme and not by need.

This study corroborates the argument that the design of the SGSSS displays a structural inequity [1,39], i.e. individuals under the subsidized scheme use the health services less than those under the contributory scheme because the benefits package offered is smaller. Thus the principle of horizontal equity is violated by the design of the health system itself, as it determines that the use of health services depends on the type of SGSSS scheme the individual is enrolled in instead of on the individual's health needs. It will be necessary to analyze what has occurred since the new law came into effect to make the benefits package equal in the two schemes [63].

\section{(In)equity in health care services utilization in Brazil}

In the case of Brazil, this study is consistent with previous research in terms of the existence of inequities in access to the health services in spite of the fact that it has a national health system $[25,26,64]$, and it also contributes new results: inequity in utilization varies according to care level and is more pronounced in outpatient secondary care and preventive services. There are authors who point out that inequity in access has been reduced in recent years [5,6], although this statement should be treated with caution as they do not distinguish between care levels.
At the primary care level there is inequality in favor of the poorest (i.e. it is pro-poor), meaning that lowerincome individuals make greater use of this level, which is the direct opposite of the situation in secondary care. This phenomenon has been described in previous research conducted in other countries with a national health system $[8,32,33,65]$. Inequity in health care utilization is concentrated at the secondary level, which might be due to the fact that higher-income individuals access private secondary care services directly (via a private health plan or outof-pocket payment) instead of accessing secondary care through the SUS [66], in order to avoid the significant access barrier of long waiting times in the SUS [62,67]. The lack of specific studies differentiating between these two levels of care in Brazil hinders the comparison of results.

In emergency care no inequities were observed, although the utilization prevalence shows that use falls as per capita income rises and may signal a higher level of use among the poorest, which could be the consequence of the presence of access barriers at the primary care levels, such as the lack of doctors or low levels of health problem resolution reported in other studies [62].

Furthermore, the results show that people with a private health plan have more access to all levels of care than those without, thus the private health plan facilitates access to services [65], but nonetheless income inequalities persist within this group. This may be a result of the existing inequalities in relation to the coverage offered in private health plans, since higher-income individuals pay for more expensive plans, which offer better coverage in terms of complementary tests and medical exams [64].

\section{(In)equity in preventive activities in both countries}

In terms of preventive activities, our study once again reveals inequities in both countries that benefit individuals with a higher socioeconomic status. Only a few studies in Colombia on access to preventive activities analyze specific activities, and those assess inequalities in access to mammography [68] or cervical cytology [69], which hinders their comparison with our results. De Charry et al. pointed out that women in the contributory scheme reported higher levels of mammography services utilization [68]. In Brazil, some studies identify lower odds of having had a mammography among women with a low educational level, low family income and no private health plan [70,71].

Moreover, as our results in Brazil corroborated, inequalities have been described in the preventive use of dental services in the south of the country [72] and other authors reveal inequalities in the use of dental services without differentiating between curative and preventive visits [5]. Furthermore, studies in both countries that do not distinguish between the types of activity 
identify that the higher the individual's socioeconomic level, the higher the probability that the medical visit was for preventive rather than curative reasons $[7,28,35]$. This cycle, in which the poor (lower-income, subsidized scheme and uninsured individuals in Colombia, and those without a private health plan in Brazil) have worse health and worse access to curative health care and preventive activities, makes them particularly vulnerable and may be related to worse health outcomes.

Finally, we should bear in mind that the evaluation of equity in access based on the use of services has been widely criticized for ambiguities in its interpretation: it is difficult to differentiate between necessary use and excessive or insufficient use, both in terms of quantity and quality of care received [73]. In this study, quality of care has not been assessed, although in both countries some results suggest that care quality varies according to socioeconomic level. In Colombia, fewer subsidized scheme enrollees reported that their health problem was solved than contributory scheme enrollees. In Brazil, higherincome individuals reported higher levels of positive outcomes [62]. As there is insufficient data to serve as evidence, further evaluation of equity in access to health services is required, focusing not only on utilization of services but also on quality of care.

\section{Conclusions}

In Colombia and Brazil the health systems have not achieved the equity in utilization prescribed in their laws. Inequity in the utilization of services varies according to care level. It is most noticeable at the secondary care level; only the use of emergency care in Brazil does not show inequities by socioeconomic status. The inequities found in both countries illustrate the close relationship between health services utilization and the design of each health system. Twenty years after the reforms, Colombia, a managed competition model with two insurance schemes, has managed to increase SGSSS enrollment but the benefits packages are still different and remain tied to the purchasing power of the population, which creates conditions of unequal access for equal need. In Brazil, despite universal coverage under the SUS there are still significant inequities in access, especially with regard to outpatient secondary care. The existence of a health system formed by the SUS, steered by principles of equity and universal coverage, together with the private sector, driven by liberalist principles, generates a pattern of inequality in access to the continuum of care. In both countries inequity in the preventive services also points to inequalities at the primary care level.

\section{Competing interests}

The authors declare that they have no competing interests.

\section{Authors' contributions}

IV and MLV were responsible for the study design and the supervision of all research phases. IG, IV, ASM, MRF and MLV were in charge of the supervision of the fieldwork. IG supervised the data entry, was responsible for the data cleaning, statistical analysis and its interpretation, and drafted the text. IV, $\mathrm{CB}$ and $\mathrm{MLV}$ contributed to the data analysis and writing of the article. ASM, PdP, MRF, JPU and CB participated in data interpretation. All authors reviewed and approved the final version of the article. The authors alone are responsible for the content of this paper.

\section{Acknowledgements}

The authors are most grateful to the people that participated in the study and generously gave their time. We thank Kate Bartlett for her help in correcting the English version of this article. This article forms part of the doctoral dissertation of Irene Garcia-Subirats at the Universitat Pompeu Fabra of Barcelona.

\section{Funding}

The research leading to these results received funding from the European Union's Seventh Framework Program (FP7/2007-2013) under grant agreement $n^{\circ}$ 223123. Moreover, a grant from the Ministry of Foreign Affairs and Cooperation for Development (Spain) was awarded to Irene GarciaSubirats for the development of the fieldwork (Beca MAEC-AECID 2010-2011 and 2011-2012). The funding sources had no involvement in study design, nor in the collection, analysis and interpretation of the data, nor in writing the article and the decision to submit it for publication.

\section{Author details}

${ }^{1}$ Health Policy and Health Services Research Group, Health Policy Research Unit, Consortium for Health Care and Social Services of Catalonia, Avenida Tibidabo, 21, Barcelona 08022, Spain. ${ }^{2}$ Ph. D. Programme in Biomedicine, Department of Experimental and Health Sciences, Universitat Pompeu Fabra, Barcelona, Spain. ${ }^{3}$ Escuela de Medicina y Ciencias de la Salud, Universidad del Rosario, Calle 14, Número 6-25, Bogotá, Colombia. ${ }^{4}$ The Prince Leopold Institute of Tropical Medicine, Nationalestraat 15, Antwerpen, Belgium. ${ }^{5}$ FIOCRUZ/PE, Brazil, Universidade de Pernambuco, Av. Agamenon Magalhães, S/N, Recife, Brazil. ${ }^{6}$ Agència de Salut Pública de Barcelona, Plaça Lesseps 1, Barcelona 08023, Spain. ${ }^{7}$ Universitat Pompeu Fabra, Barcelona, Spain. ${ }^{8}$ Ciber of Epidemiology and Public Health (CIBERESP), Madrid, Spain.

Received: 2 August 2013 Accepted: 24 January 2014

Published: 31 January 2014

\section{References}

1. Vargas I, Vázquez ML, Jane E: Equity and health systems reform in Latin America. Cad Saude Publica 2002, 18(4):927-937.

2. Culyer AJ, Wagstaff A: Equity and equality in health and health care. $J$ Health Econ 1993, 12(4):431-457.

3. van Doorslaer E, Wagstaff A, van der Burg H, Christiansen T, Citoni G, Di Biase R, Gerdtham UG, Gerfin M, Gross L, Häkinnen U, et al: The redistributive effect of health care finance in twelve OECD countries. J Health Econ 1999, 18(3):291-313.

4. Suárez-Berenguela RM: Health System Inequalities and Inequities in Latin America and the Caribbean: Findings and policy implications. Working document prepared for the Health and Human Development Division of the Pan American Health Organization-World Health Organization. Geneva: WHO; 2000.

5. Macinko J, Lima Costa MF: Horizontal equity in health care utilization in Brazil, 1998-2008. Int J Equity Health 2012, 11:33.

6. Almeida G, Sarti FM, Ferreira FF, Diaz MD, Campino AC: Analysis of the evolution and determinants of income-related inequalities in the Brazilian health system, 1998-2008. Rev Panam Salud Publica 2013, 33(2):90-97.

7. Ruiz Gómez F, Zapata Jaramillo T, Garavito Beltran L: Colombian health care system: results on equity for five health dimensions, 2003-2008. Rev Panam Salud Publica 2013, 33(2):107-115.

8. Hanratty B, Zhang T, Whitehead M: How close have universal health systems come to achieving equity in use of curative services? A systematic review. Int J Health Serv 2007, 37(1):89-109.

9. The World Bank Group: Data Colombia. 2013. http://data.worldbank.org/ country/colombia. 
10. The World Bank Group: Data Brazil. 2013. http://data.worldbank.org/ country/brazil.

11. The World Bank Group: How we Classify Countries. 2013. http://data. worldbank.org/about/country-classifications/country-and-lending-groups.

12. Bárcena A, Prado A, Hopenhayn M, Beccaria L, Jaspers-Faijer D, Quarless D, Pérez R: Panorama Social de América Latina. Santiago de Chile: United Nations Publications; 2012.

13. Organización Panamericana de la Salud: Información y Análisis de Salud: Situación de Salud en las Américas: Indicadores Básicos 2013. Washington, D.C: OPS; 2013.

14. República de Colombia: Ley 100/1993, de 23 de diciembre, por la cual se crea el Sistema de Seguridad Social Integral y se dictan otras disposiciones. Diario Oficial n. 41. 23/12/1993.

15. Profamilia: Encuesta Nacional de Demografía y Salud-ENDS 2010. Bogotá: Profamilia; 2010.

16. Morales LG: El financiamiento del sistema de seguridad social en salud en Colombia. Santiago de Chile: United Nations Publication; 1997.

17. Presidência da República: Constituição da República Federativa do Brasil. Brasilia; 1988.

18. Mesa-Lago C: O sistema de saúde brasileiro: seu impacto na pobreza e na desigualdade. ABACO Revista de Cultura y Ciencias Sociales 2007, 41:115-131.

19. Hernandez M: Health reform, equity and the right to health in Colombia. Cad Saude Publica 2002, 18(4):991-1001.

20. Ocke-Reis CO, Marmor TR: The Brazilian national health system: an unfulfilled promise? Int J Health Plann Manage 2010, 25(4):318-329.

21. Sousa MF: The family health program in Brazil: analysis of access to basic care. Rev Bras Enferm 2008, 61(2):153-158.

22. Restrepo $\mathrm{JH}$, Zambrano A, Vélez M, Ramírez M: Health insurance as a strategy for access: streamlined facts of the Colombian Health Care Reform. Bogotá: Universidad del Rosario; 2007.

23. Paim J, Travassos C, Almeida CM, Bahia L, Macinko J: The Brazilian health system: history, advances, and challenges. Lancet 2011, 377(9779):1778-1797.

24. Céspedes JE, Jaramillo-Pérez I, Martínez R, Olaya S, Reynales J, Uribe C, Castaño R, Garzón E, Almeida C, Travassos C, et al: Efectos de la reforma de la Seguridad Social en Salud en Colombia sobre la equidad en el acceso y la utilización de servicios de salud. Rev Salud Publica (Bogota) 2000, 2(2):145-164.

25. Travassos $C$, Viacava F, Pinheiro $R$, Brito A: Utilization of health care services in Brazil: gender, family characteristics, and social status. Rev Panam Salud Publica 2002, 11(5-6):365-373

26. Cataife $\mathrm{G}$, Courtemanche $\mathrm{CJ}$ : Is universal health care in Brazil really universal? 2011. http://papers.ssrn.com/sol3/papers.cfm? abstract id $=1690662$.

27. Flórez C, Soto V, Acosta O, Karl C, Misas J, Forero N, Lopera C: Avances y desafíos de la equidad en el sistema de salud colombiano. Bogotá: Fundación Corona; 2007.

28. Mejía-Mejía A, Sanchez-Gandur AF, Tamayo-Ramirez JC: Equity in access to health-services in Antioquia, Colombia. Rev Salud Publica (Bogota) 2007, 9(1):26-38.

29. da Costa JS D, Reis MC, Silveira Filho CV, Linhares RS, Piccinini F: Prevalence of medical visits and associated factors, Pelotas, Southern Brazil, 1999-2000. Rev Saude Publica 2008, 42(6):1074-1084.

30. Giatti L, Barreto SM: Labor market status and the use of healthcare services in Brazil. Cien Saude Colet 2011, 16(9):3817-3827.

31. Viacava F, Souza-Junior PR, Szwarcwald CL: Coverage of the Brazilian population 18 years and older by private health plans: an analysis of data from the World Health Survey. Cad Saude Publica 2005, 21(Suppl):119-128.

32. Garrido-Cumbrera M, Borrell C, Palencia L, Espelt A, Rodriguez-Sanz M, Pasarin Ml, Kunst A: Social class inequalities in the utilization of health care and preventive services in Spain, a country with a national health system. Int J Health Serv 2010, 40(3):525-542.

33. Palencia L, Espelt A, Rodriguez-Sanz M, Rocha KB, Pasarin MI, Borrell C: Trends in social class inequalities in the use of health care services within the Spanish National Health System, 1993-2006. Eur J Health Econ 2013, 14(2):211-219.

34. van Doorslaer $E$, Masseria C, Koolman X: Inequalities in access to medical care by income in developed countries. CMAJ 2006, 174(2):177-183.

35. Pinheiro RS, Viacava F, Travassos C, Brito A: Gender, morbidity, access and utilization of health services in Brazil. Cien Saude Colet 2002, 7(4):687-707.
36. Díaz-Grajales C, Zapata-Bermúdez Y, Aristizábal-Grisales JC: Access to preventive services in contributive and subsidized regimes of health in a (slums) stratum two neighoborhood of the city of Cali. Rev Geren Polit Salud 2011, 12(21):153-175.

37. Ruiz F, Amaya L, Venegas S: Progressive segmented health insurance: Colombian health reform and access to health services. Health Econ 2007 16(1):3-18.

38. Giedion U, Díaz BY, Alfonso EA, Savedoff WD: The Impact of Subsidized Health Insurance on Health Status and on Access to and Use of Health Services. In From few to many: Ten Years of Health Insurance Expansion in Colombia. Edited by Glassman A, Giuffrida A, Escobar ML, Giedion U. Washington, D.C: Inter-American Development Bank and the Brookings Institutions; 2009.

39. Yepes FJ, Ramírez M, Sánchez LH, Ramírez ML, Jaramillo I: Luces y sombras de la reforma de la salud en Colombia. Bogotá: Centro internacional de investigaciones para el desarrollo; 2010.

40. Travassos C, de Oliveira EXG, Viacava F: Geographic and social inequalities in the access to health services in Brazil: 1998 and 2003. Cien Saude Colet 2006, 11(4):975-986.

41. Dachs JN, Ferrer M, Florez CE, Barros AJ, Narvaez R, Valdivia M: Inequalities in health in Latin America and the Caribbean: descriptive and exploratory results for self-reported health problems and health care in twelve countries. Rev Panam Salud Publica 2002, 11(5-6):335-355.

42. Rubio-Mendoza ML: Equity in gaining access to health services and equity in funding being attended by them in Bogota. Rev Salud Publica (Bogota) 2008, 10(Suppl):29-43.

43. Capilheira MF, da Silva Dos Santos I: Individual factors associated with medical consultation by adults. Rev Saude Publica 2006, 40(3):436-443.

44. da Costa JS D, Presser AD, Zanolla AF, Ferreira DG, Perozzo G, Freitas IB, Portolan LT, Tavares RT, Olinto MT, Pattussi MP: Use of outpatient health services by women: a population-based study in southern Brazil. Cad Saude Publica 2008, 24(12):2843-2851.

45. Bastos GA, Duca GF, Hallal PC, Santos IS: Utilization of medical services in the public health system in the Southern Brazil. Rev Saude Publica 2011, 45(3):475-54

46. Pessoto UC, Heimann LS, Boaretto RC, Castro IE, Kayano J, Ibanhes LC Junqueira $V$, da Rocha $J$, Barboza R, Cortizo CT, et al: Health care services utilization and access inequalities in the Sao Paulo Metropolitan Region. Cien Saude Colet 2007, 12(2):351-362.

47. Homedes N, Ugalde A: Neoliberal reforms in health services in Latin America: a critical view from two case studies. Rev Panam Salud Publica 2005, 17(3):210-220.

48. Levino A, Carvalho EF: Comparative analysis of health systems on the triple border between Brazil, Colombia, and Peru. Rev Panam Salud Publica 2011, 30(5):490-500.

49. Almeida CM, Travassos C, Porto S, Labra ME: Health sector reform in Brazil: a case study of inequity. Int J Health Serv 2000, 30(1):129-162.

50. Wallace SP, Gutierrez VF: Equity of access to health care for older adults in four major Latin American cities. Rev Panam Salud Publica 2005, 17(5-6):394-409.

51. Esteves RJF: The quest for equity in Latin America: a comparative analysis of the health care reforms in Brazil and Colombia. Int J Equity Health 2012, 11(6). doi:10.1186/1475-9276-11-6.

52. Vázquez ML, da Silva MR F, Unger JP, Mogollón AS, Vargas I, De Paepe P: Impact on equity of access and efficiency of Integrated Health care Networks (IHN) in Colombia and Brazil. Equity-LA project id: 223123 (2008-2013). 2013. http://www2.equity-la.eu/publications/technical-reports?set_language=en.

53. Aday LA, Andersen R: A framework for the study of access to medical care. Health Serv Res 1974, 9(3):208-220.

54. Vargas I, Vázquez ML, Mogollón AS, Unger JP: Barriers of access to care in a managed competition model: lessons from Colombia. BMC Health Serv Res 2010, 10:297.

55. Vargas I, Unger JP, Mogollón AS, Vázquez ML: Effects of managed care mechanisms on access to healthcare: results from a qualitative study in Colombia. Int J Health Plann Manage 2013, 28(1):e13-e33.

56. Vanderlei LCM: Mortalidade infantil evitável e acesso à atenção à saúde no Recife, Brasil na perspectiva dos principais atores sociais, PhD thesis. Barcelona: Universitat Autònoma de Barcelona; 2010

57. Vargas I: Barreras en el acceso a la atención en salud en modelos de competencia gestionada: un estudio de caso en Colombia, PhD thesis. Barcelona: Universitat Autònoma de Barcelona; 2009. 
58. Vanderlei LCM, Vázquez ML: Preventable infant mortality and barriers to access to primary care in Recife, Northeastern Brazil. Rev Saude Publica 2013, 47(2):379-389.

59. O'Halloran J, Miller GC, Britt H: Defining chronic conditions for primary care with ICPC-2. Fam Pract 2004, 21(4):381-386.

60. Kunst A: Cross-national comparisons of socio-economic differences in Mortality PhD thesis. Rotterdam: Eramus University; 1997.

61. StataCorp: Stata Statistical Sorftware: Release 12. College Station, TX: StataCorp LP; 2011.

62. Garcia-Subirats I, Vargas I, Mogollón AS, De Paepe P, Silva MR, Unger JP, Vázquez ML: Barriers in access to healthcare in countries with different health systems. A study in municipalities of central Colombia and north-eastern Brazil. Soc Sci Med 2013. in press.

63. República de Colombia: Acuerdo por el cual se unifican los Planes Obligatorios de Salud de los Regímenes Contributivo y Subsidiado a nivel nacional. Acuerdo número 032: Comisión de Regulación en Salud; 2012.

64. Neri M, Soares W: Social inequality and health in Brazil. Cad Saude Publica 2002, 18(Suppl):77-87.

65. Borrell C, Palencia L, Rodriguez-Sanz M, Malmusi D, Bartoll X, Puigpinos R Trends in social inequalities in health in Catalonia, Spain. Med Clin (Barc) 2011, 137(Suppl 2):60-65.

66. Porto SM, Uga MA, Moreira RS: An analysis of use of the health services by financing system: Brazil 1998-2008. Cien Saude Colet 2011, 16(9):3795-3806.

67. Solla J, Chioro A: Atenção ambulatorial especializada. In Politicas e Sistema de Saúde no Brasil. Edited by Giovanella L, Escorel S, Costa Lobato LV, Noronha JC, de Carvalho I. Rio de Janeiro: Fiocruz Editora, CEBES; 2009:627-998.

68. Charry LC, Carrasquilla G, Roca S: Equity regarding early breast cancer screening according to health insurance status in Colombia. Rev Salud Publica (Bogota) 2008, 10(4):571-582.

69. Ivan Lucumi CD, Gomez Gutierrez LF: Accessibility to healthcare services in the recent cervical cytology performed in an urban area in Colombia. Rev Esp Salud Publica 2004, 78(3):367-377.

70. Lages RB, Oliveira GP, Simeão Filho VM, Nogueira FM, Teles JBM, Vieria SC: Inequalities associated with lack of mammography in Teresina-Piauí-Brazil, 2010-2011. Rev Bras Epidemiol 2012, 15(4):737-747.

71. de Oliveira EX, Pinheiro RS, Melo EC, Carvalho MS: Socioeconomic and geographic constraints to access mammography in Brasil, 2003-2008. Cien Saude Colet 2011, 16(9):3649-3664.

72. Camargo MB, Dumith SC, Barros AJ: Regular use of dental care services by adults: patterns of utilization and types of services. Cad Saude Publica 2009, 25(9):1894-1906

73. Hulka BS, Wheat JR: Patterns of utilization. The patient perspective. Med Care $1985,23(5): 438-460$

doi:10.1186/1475-9276-13-10

Cite this article as: Garcia-Subirats et al:: Inequities in access to health care in different health systems: a study in municipalities of central Colombia and north-eastern Brazil. International Journal for Equity in Health 2014 13:10.

\section{Submit your next manuscript to BioMed Central and take full advantage of:}

- Convenient online submission

- Thorough peer review

- No space constraints or color figure charges

- Immediate publication on acceptance

- Inclusion in PubMed, CAS, Scopus and Google Scholar

- Research which is freely available for redistribution 